\title{
The enduring value of Bulgakov's stories
}

\author{
A Young Doctor's Notebook \\ Mikhail Bulgakov (translation by Hugh \\ Aplin) \\ Oneworld Classics; 2011
}

$\mathrm{W}$

hile the very best of literature possesses a measure of timelessness or universality - Great Expectations, for example, has been read for 150 years by everyone everywhere who loves fiction, and this will likely be true for at least another 150 years - I find that fiction about medicine rarely attains this height. Thomas Mann's The Magic Mountain, for example, is a fantastic manual for the extremely limited constituency of hypochondriac modernists. In The House of God, Samuel Shem achieves a particular strain of relentless cynicism that already seems dated.

Is it true, then, that universally affecting stories cannot be written about medicine, about illness and healing, about - ultimately - living and dying? Is our experience of these things so dependent upon time, place and cul-

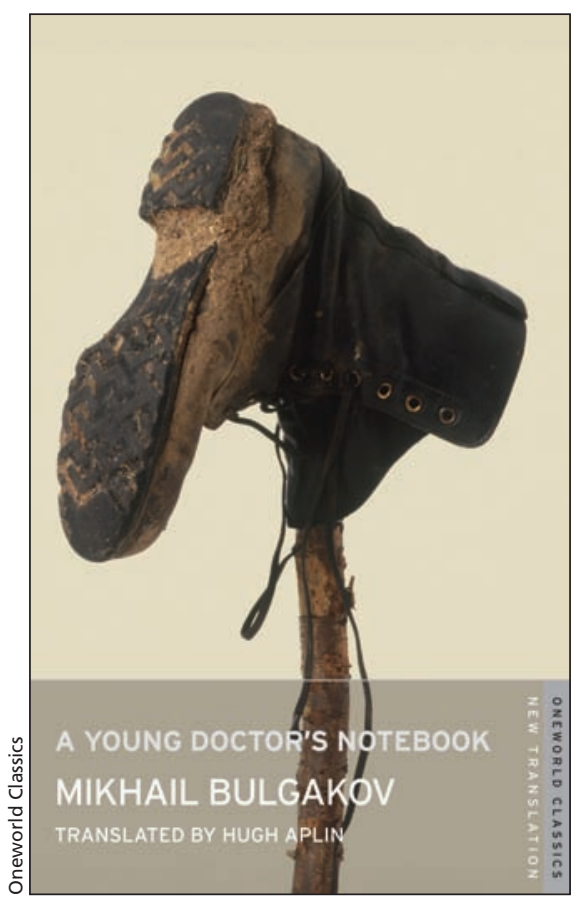

inexperienced physician in rural Russia. His style is one of brisk pacing and unadorned prose; in this new edition, the essential Slavic directness of the language is convincingly translated into English by Hugh Aplin. The

\section{Is it true, then, that universally affecting stories cannot be written about medicine?}

ture as to prevent us from connecting to stories that are not proximate to our own experiences?

Mikhail Bulgakov's collection A Young Doctor's Notebook contradicts this position quite effectively. Essentially fictionalized autobiography, these are stories of Bulgakov's time as an resulting stories are engaging, as funny and morbid as would be expected of a literary descendant of Anton Pavlovich Chekhov or Alexsandr Pushkin.

In "The Steel Throat," for example, Bulgakov is faced with the prospect of performing a tracheotomy, a procedure he has never seen or performed, on a child with diphtheria. When the family resists, he is elated: "Well, that's it then! That makes it easier for me. I told them, made the offer ... They've refused and I'm saved." Quite in spite of himself, however, he insists, and the family consents. When the procedure seems not to be going well, the melodrama deepens: “... now she's going to die with her throat torn apart, and there's no way I can ever prove that she would have died anyway ...". Further problems push the young doctor to the end of his rope: "As soon as I get home, I'll shoot myself."

This is the essence of being in over one's head, brilliantly rendered. The setting is, in every respect, far from my own experience - I've never even seen a patient with diphtheria! - but it was not difficult to connect with the tale. In another story, "The Blizzard," Bulgakov is very nearly done in by a winter storm; the Russian winter is a nihilist adversary very different from the frolicking Canadian season. But the fear is nevertheless gripping.

Notebook concludes with "Morphine," its longest and perhaps best story. Nothing resembling this harrowing descent into addiction has happened to me, but in another time and place it might have. And there we have, nearly a century later, the enduring value of Bulgakov's stories.

\section{Paul Moorehead MD}

Research fellow

Pathology and Molecular Medicine

Queen's University

Kingston, Ont.

CMAJ 2012. DOI:10.1503/cmaj.112176 